\title{
How Does the First Job Matter for an Individual's Career Life in Japan?
}

\author{
Junya Hamaaki, Masahiro Hori, Saeko Maeda, and Keiko Murata ${ }^{\dagger}$
}

\begin{abstract}
Exploiting annual career records of female workers constructed from the Japanese Panel Survey of Consumers (JPSC), this paper examines how the first job matters for an individual's future job career. Using the regional unemployment rate in the year of graduation as an instrument for the first job status (i.e., regular job or not), we confirm that an individual's first job status matters significantly for the future job status even for female workers in Japan, although the effect gradually declines over the years and effectively disappears within around ten years from graduation. However, the observed first job effect appears to depend on the post-graduation career path taken by an individual, in the sense that someone who was unsuccessful during the first job hunt at the time of graduation can make up for the negative effect if she is lucky enough to secure a job as a regular employee within a reasonable time period.
\end{abstract}

JEL classification codes: J13; J62

Keywords: youth labor market; initial labor market conditions; cost of recessions; Japan

\footnotetext{
${ }^{\dagger}$ All four authors are affiliated with the Economic and Social Research Institute, Cabinet Office, Government of Japan. Hori is also with Hitotsubashi University, and Murata is with Tokyo Metropolitan University. We are grateful to Ayako Kondo, Souichi Ohta and Ralph Paprzycki for their valuable comments on an earlier draft of this paper. We would also like to thank Kazumasa Iwata and other ESRI colleagues for their support. In addition, we would like to thank the Institute for Research on Household Economics for permitting us to use the longitudinal data from the Japanese Panel Survey of Consumers. Murata gratefully acknowledges financial support from the Grant-in-Aid for Scientific Research (C) 21530202 from the Japan Society for the Promotion of Science (JSPS). The views expressed in this paper are those of the authors and do not represent those of any of the institutions that the authors belong to.

Corresponding authors: Keiko Murata (keiko-murata@tmu.ac.jp) and Masahiro Hori (mhori@,ier.hit-u.ac.jp)
} 


\section{Introduction}

New school graduates just having completed their education and in search of a job inevitably will have to contend with the macroeconomic situation in their year of graduation. While those who graduate in a good year are likely to find a desirable job, those who graduate in a bad year may be forced to start with a less attractive job or find themselves unemployed due to a lack of employment opportunities. In Japan, the unemployment rate rose substantially during the 1990s and remained high during the 2000s due to the prolonged period of slow growth and repeated recessions following the burst of the bubble economy. In particular the unemployment rate of the young, which increased from 4 to 10 percent, is causing concern, as young workers who are unable to find a good job upon graduation tend to remain jobless or work as part-time (or temporary) employees in subsequent years. This negative cohort effect impinging on those who graduated during the protracted recession, and especially in what came to be called the employment "ice age" (around 1998-2002), has become an important policy issue in contemporary Japan.

Recent academic studies have found that macroeconomic conditions at labor market entry have a significant impact on individuals' working conditions not only in their entry year but also in subsequent years. Oreopoulos et al. (2006), for example, focusing on Canadian college graduates, found substantial initial earning losses for those who graduated in bad years, which linger for up to around ten years before dissipating. Similarly, Kahn (2010), using U.S. data for white male college-educated workers who graduated in a bad year, found long-run negative effects on wages as well as on occupational attainment. Several studies on other countries also find persistent cohort effects from macroeconomic conditions at graduation, including Brunner and Kuhn (2009) for Austria as well as Ohtake and Inoki (1997), Kondo (2008), and Genda et al. (2010) for Japan. ${ }^{1}$

While the persistence of cohort effects in the labor market is well established, the mechanisms underlying these effects are not necessarily well understood. Although there are various possible theoretical explanations of the persistency of such effects, such as search costs, the accumulation of human capital

\footnotetext{
1 "Brunner and Kuhn (2009), moreover, provide a brief survey of recent empirical studies, while Genda et al. (2010) provides a comparison of such effects in Japan and the United States.
} 
through work experience, or signaling effects, that is, the stigma caused by the failure to find a job on graduation, there are few empirical studies examining the pertinence of the different explanations, since few datasets containing the career records of individuals, which are necessary to examine the underlying mechanisms, are available.

Against this background, studies on the effect of individuals' first job (in the absence of data on individuals' entire job career history) represent an empirical attempt to explore the underlying mechanisms. If the first job matters for an individual's future career, the very least that can be argued is that there is a negative cohort effect from a recession that falls unevenly on individuals who were unsuccessful in their hunt for their first job, rather than evenly on every individual in the cohort. Moreover, investigation of the effect of individuals' first job on their future careers could be helpful in gaining a better understanding of the underlying mechanisms of the cohort effects. For example, Oyer (2006) examined the work status of economics Ph.D.s. in relation to their first job obtained at graduation. Instrumenting macroeconomic conditions with the demand for economists in the year an individual graduated, he finds that there is a causal link between the quality of an economist's first job and that of his/her position anywhere from three to fifteen years later. Focusing on individuals' research productivity, he further finds that, for academics, getting a good first job increases publication productivity in the following ten years, indicating that economists develop task-specific human capital if they find a good job from the start.

Similar studies on Japanese individuals are relatively scarce. An exception, however, is Kondo (2007), who shows that individuals' current employment status is closely linked to their first job. Specifically, she finds that the probability of being a regular employee is substantially lower (even several years after graduation) if an individual failed to obtain a job as a regular employee at graduation. She suggests that a possible reason for this finding is the signaling effect: in Japan, companies rarely upgrade temporary or part-time workers to regular worker status, and potential employers cannot distinguish between lucky individuals who obtained a full-time regular job at graduation and a possibly more able (but unlucky) individual who failed to get one at entry.

There are reasons to believe that the first job effect is likely to be more important in Japan than in 
other countries. Since lifetime employment is an important element of the employment system in Japan, workers are implicitly assumed to start out their job career immediately after graduation and continue to work in the same firm until they reach retirement age. This means the standard route of recruitment is the recruitment of new graduates, and if an individual fails to find a desirable job at graduation, it becomes very difficult to find alternatives in subsequent years, since the failure to land a job as a regular employee at graduation is sometimes regarded as a stigma by potential employers. This conjecture is consistent with the results of a study by Genda et al. (2010) focusing on less-educated male workers in Japan and the United States, which finds negative persistent effects of the unemployment rate at graduation in Japan, while in the United States such effects are only temporary.

Against this background, this paper seeks to examine in more detail how the first job matters for an individual's future job career in Japan, using micro-data for female individuals taken from the Japanese Panel Survey of Consumers (JPSC). While the presence of first job effects in Japan has already been established by Kondo (2007), the structure of her dataset, i.e., pooled cross-sectional survey data from 1999 to 2002, prevented her from investigating the processes and mechanisms underlying these effects. Using a long-run panel surveyed from 1993 to 2006, which also collects job career records (from school graduation) for individual female workers in Japan, we first test whether the central findings on Japanese workers by Kondo (2007) are supported by our much larger and more recent dataset, which includes individuals who graduated in the so-called employment "ice age" (around 1998-2002). We then examine how the first job effect evolves with the passage of time after their graduation by analyzing career records of individuals collected by the JPSC. By taking advantage of the long-run panel, through which we can track the annual career records of individuals from their school/university graduation, we finally examine how the first job effect differs depending on individuals' career path in the first few years after graduation.

The findings can be summarized as follows. First, our results confirm that an individual's employment status immediately after graduation matters for the employment status in subsequent years even for female workers in Japan. Second, we find that the effect appears to gradually decline over the years and effectively disappears up to around ten years from graduation. Third, we find that the first job 
effect appears to depend on the post-graduation career path taken by an individual. That is to say, the future job opportunities for individuals who were able to find a regular job within three years from graduation (in spite of their failure to find a regular job immediately after graduation) are not significantly different from those for individuals who found a regular job at graduation. This finding suggests that indeed the signaling effect plays a large role in the first job effect, since the negative first job effect essentially disappears for individuals who were fortunate enough to secure employment as a regular employee within a reasonable time period after graduation. However, this also implies that if bad years carry on for a prolonged period as was the case during the "lost decade" more generally and the employment "ice age" around the turn of the millennium in particular - a large number of unfortunate new graduates will lack the opportunity to dispel the unfounded stigma attached to not finding regular employment upon graduation and will therefore experience negative effects for a considerable period in their career life.

The rest of the paper proceeds as follows. The next section describes the data used and the empirical strategy of our analysis. Section 3 reports the results of our empirical analysis on the three key questions we address: (1) whether the existence of a first job effect can be confirmed; (2) how long the first job effect persists; and (3) whether the initial effect is contingent on the career path taken by individuals in the first few years after graduation. Section 4 concludes.

\section{Data and methodology}

\subsection{Data}

The dataset we use is the micro data from the Japanese Panel Survey of Consumers (JPSC) conducted by the Institute for Research on Household Economics. The JPSC was originally designed as an in-home questionnaire survey (over multiple periods) to track a random sample of 1,500 single and married women aged between 24 and 34 who were selected from throughout Japan in 1993. To make up for attrition over the years, 500 women aged 24-27 were added in 1997 and 1,000 women aged 24-29 were added in 2003. Respondents are surveyed once a year in October and thus fourteen waves of data from 1993 to 2006 are currently available. 
The JPSC provides information on whether each respondent is a regular employee, a part-time or temporary worker, or not in employment, as well as some other characteristics such as age, education, marital status, and family structure. It also asks about respondents' first occupation immediately after graduation and, regardless of academic qualification, about the labor status (regular employee, part-time or temporary employee, or not in employment) each year since age 18. Even though the JPSC does not include respondents under 24 years of age, by making use of the job history record together with other relevant information obtained, we can construct a large dataset covering individuals from their graduation onward (see the Appendix for details on the construction of the dataset). Our dataset consists of 21,666 observations covering 1,830 individuals, compared to 1,406 in the dataset used by Kondo (2007), and includes individuals who graduated after 1998, when Japanese labor market conditions were particularly severe.

Table 1 reports the descriptive statistics of the dataset that we use in the following analysis. It should be noted that we excluded from our dataset respondents who were students. We also excluded individuals who were working in a family business, as independent professionals, as self-employed workers, and as homeworkers, since the question on their job status, i.e., whether they are regular employees or not, does not apply. Of the 21,666 observations in our dataset, around half are high school graduates and the remainders are college graduates or higher, since we dropped the very small number of junior high school graduates. The share of those who landed a job as a regular employee at graduation in our dataset is around 80 percent, which is close to the share indicated by official statistics. 54 percent of the observations in our dataset are married, and 42 percent have a child or children.

\section{2-2. Empirical strategy}

To measure the effect of the initial employment status on the current employment status, we start with the following binary choice model:

$$
y_{i t}= \begin{cases}1 & \left(\text { if } \quad y_{i t}^{*}=\alpha x_{i}+\beta^{\prime} Z_{i t}+\varepsilon_{i t}>0\right) \\ 0 & \text { (if } \left.\quad y_{i t}^{*}=\alpha x_{i}+\beta^{\prime} Z_{i t}+\varepsilon_{i t} \leq 0\right)\end{cases}
$$


where $y_{i t}$ is a dummy variable that takes one if individual $i$ worked as a regular employee in year $t$ and zero otherwise and $x_{i}$ is a dummy that takes one if individual $i$ worked as a regular employee immediately after graduation and zero otherwise. $Z_{i t}$ is a vector of other control variables, and $\varepsilon_{i t}$ is the error term and is assumed to follow a normal distribution. However, as discussed by Kondo (2007), both $y_{i t}$ and $x_{i}$ may be affected by unobservables such as individuals' ability or motivation and that may be correlated. Therefore, to take into account this potential endogeneity bias, we estimate the following simultaneous probability model:

$$
\begin{aligned}
& y_{i t}= \begin{cases}1 & \text { if } \left.\quad y_{i t}^{*}=\alpha x_{i}+\beta_{1}^{\prime} Z_{1, i t}+\beta_{2}^{\prime} Z_{2, i}+\varepsilon_{i t}>0\right) \\
0 & \text { if } \left.\quad y_{i t}^{*}=\alpha x_{i}+\beta_{1}^{\prime} Z_{1, i t}+\beta_{2}^{\prime} Z_{2, i}+\varepsilon_{i t} \leq 0\right)\end{cases} \\
& x_{i}= \begin{cases}1 & \text { if } \left.\quad x_{i}^{*}=\gamma^{\prime} v_{i}+\delta Z_{2, i}+\mu_{i}>0\right) \\
0 & \text { (if } \left.\quad x_{i}^{*}=\gamma^{\prime} v_{i}+\delta Z_{2, i}+\mu_{i} \leq 0\right)\end{cases}
\end{aligned}
$$

where $Z_{1, i t}$ is a vector of time-variant control variables for individual $i$, including the number of years since graduation, and family-related factors, such as a dummy variable for marital status, a dummy variable for living with a child aged 6 or below, a dummy variable for living with a child aged 7 to 18 , as well as the actual number of children aged 6 or below and number of children aged 7 to 18 . The reason for using separate variables for children age 6 or below and aged 7 to 18 is that pre-school age children generally require more care than older children. $Z_{2, i}$ is a vector of other control variables which are determined at the time of graduation and have not varied since. In our dataset, we were able to identify only one such variable, namely, educational attainment. $v_{i}$ is a macroeconomic indicator of labor market conditions at graduation, the instrument for $x_{i}$. The two error components, $\varepsilon_{i}$ and $\mu_{i}$, are allowed to correlate, namely, $\operatorname{Cov}\left(\varepsilon_{i t}, \mu_{i} \mid Z_{1, i t}, Z_{2, i}, v_{i}\right)=\rho$.

As instrument $v_{i}$, which must be correlated with $x_{i}$ and be independent from $\varepsilon_{i t}$, we use the regional unemployment rate in the year preceding individual $i$ 's graduation. ${ }^{2}$ The regional unemployment rate is taken from the Labor Force Survey, published by the Statistics Bureau, Ministry of Internal Affairs and Communications, which reports regional unemployment rates for nine regions across Japan. We use the

\footnotetext{
${ }^{2}$ We also used the regional job opening ratio. Our conclusion, however, remained essentially unchanged.
} 
rate in the preceding year rather than the rate in the year of graduation, because in Japan, students normally start job hunting, and are offered employment, during the year leading up to their graduation. Year dummies and the current regional unemployment rate are also included in $Z_{1, i t}$ to control for macroeconomic conditions in year $t$.

\section{Results}

\subsection{Does the first job matter even for female workers in Japan?}

The basic result for equation (2) is reported in the first column of Table 2. The coefficient on the regional unemployment rate in the first-stage equation is negative and significant, as expected. The marginal effect of the first job is positive and significant, implying that if a new graduate obtains a job as a regular employee upon graduation, the probability of being a regular employee in subsequent years is 25 percentage points higher. This estimated marginal effect is smaller than the value obtained by Kondo (2007), which was 48 percentage points, for her dataset including both male and female employees. While our dataset does not allow us to make direct comparisons because the JPSC only covers women, our results indicate that the first job effect is significant even for female employees who, for family-related reasons such as getting married and having children, have relatively lower job retention rates than men. ${ }^{3}$

The estimation in the first column implicitly assumes that the first job effect is the same regardless of individuals' educational background. To examine the validity of this assumption, we divide our sample by level of education. The results are reported in the second and third columns and show that the marginal effect is slightly larger for college graduates (34 percentage points) than high school graduates (22 percentage points). This result is broadly consistent with Kondo's (2007) study, which obtains a larger first job effect for college graduates than non-college graduates, although the difference is not statistically significant. With regard to family-related factors, married women are less likely to have a regular job. If an individual has a small child or children 6 years old or younger, there is a lower probability that she will

\footnotetext{
${ }^{3}$ Kondo (2007) also reports results by gender, which suggest that the marginal effect is 28 percentage points for female workers and 47 percentage points for male workers, although both estimates are not statistically significant. She notes that this is probably due to the limited sample size.
} 
work as a regular employee, while the effect will disappear once her children have reached an age between 7 and 18.

\subsection{How long does the first job effect persist?}

Our next question is how long this initial effect persists. Since the regressor of key interest (the success/failure in job hunting at graduation) does not vary over time for any given individual, standard panel data techniques such as estimating individual-specific fixed effects cannot be used. We therefore examine the persistence of the first job effect using pooled data. In the model using pooled data (eq. 2) we replace the employment status at graduation, $x_{i}$, with the products of $x_{i}$ and dummies representing each year after graduation (from the first to the 12th year). The number of observations is 1,629 in the first year and gradually declines to 1,535 in the fifth year, 1,134 in the tenth year, and 899 in the 12th year. Figure 1 depicts the estimated marginal effect for each year after graduation. The effect gradually declines, but is statistically significant up to around ten years after graduation. Our finding that the first job effect weakens over time is largely consistent with findings of earlier studies (Genda et al. 2010, Kondo 2007). ${ }^{4}$

\subsection{Does the first job really matter?}

So far, we have confirmed that there exists a first job effect for female workers in Japan, and that the effect persists at least for several years. In this subsection, we proceed by examining a more subtle question: does the "first" job really matter? By "first" job, we mean the first job obtained immediately after graduation from school/college. Among those who were unsuccessful in their job hunt at the time of their graduation due to unfavorable macroeconomic circumstances, some are likely to have been able to find a job as a regular employee in subsequent years, especially when the economy recovered. In fact, during the period of recovery of the Japanese economy from 2003 to 2007, many enterprises are said to have broadened their search for new employees from new graduates to include "recent graduates" to make up for shortages in

\footnotetext{
${ }^{4}$ This finding is also consistent with the results obtained by Genda and Kurosawa (2001) which show that an increase in the unemployment rate at graduation raises the future probability of workers leaving employers by lowering the quality of job matches in Japan. Bowlus (1995) reports similar findings on matching quality in recessions in the United States.
} 
their workforce ${ }^{5}$. In this context, it is natural to ask whether the "first" job really matters, or in other words, whether the first job effect depends on the post-graduate career path taken by an individual. If the first job indeed does matter and the effect persists irrespective of individuals' career after (but not at) their graduation, policy measures to help those that "lost out" in their first job hunt may be recommendable. However, if the effect disappears relatively quickly for those who do find a job as a regular employee a few years after graduation, all we need to be concerned about are those who have been unable to find a job as a regular employee not only at graduation but also a few years after graduation.

Examining the path dependence of the first job effect may help not only in the design of policies but also contribute to our understanding of possible underlying mechanisms of the effect. Let us consider two groups of individuals which both graduated at the same time. However, one group was able to find a job as a regular employee at graduation, while the other managed to find a job as a regular employee only one or two years after graduation. The question that we are interested in is how this difference affects the career life of these individuals later on. If the first job effect results from the accumulation of human capital through job experiences, the negative effect for the latter group would persist, since these individuals may have accumulated less human capital due to their shorter job experience than the first group. However, if the first job effect simply is the result of a negative signal, or a stigma attached to those who were unsuccessful in their job hunt at graduation, the effect should disappear once the individuals in the second group find a job as a regular employee.

Fortunately, we can deal with this subtle question regarding the first job effect using the annual career records of individual participants in the JPSC. To examine the path dependence of the first job effect, we divide our dataset into four groups: (a) those who never had a job as a regular employee in the first three years after graduation; (b) those who could not find a job as a regular employee at graduation but found one at least once within three years after graduation; (c) those who had a regular job at graduation but answered (at least once in the survey within three years after their graduation) that they were currently not a regular

\footnotetext{
5 According to a survey covering enterprises with 300 or more employees, around 55 percent of enterprises said that in addition to new graduates, they also aimed at recruiting regular workers from among recent graduates (people who graduated within the past three years), and 95 percent of these actually did hire recent graduates in 2004 (Japan Institute for Labour Policy and Training 2005).
} 
employee; and (d) those who found a job as a regular employee at graduation and continued to work as a regular employee throughout the three years after graduation. Following the results obtained in the previous subsection that the first job effect is significant up to around ten years after graduation, we limit our observations to those for whom ten years or less have passed since graduation.

The first column of Table 3 reports the result when we include all four groups of observations and estimate equation (2), excluding observations whose number of years since graduation is less than four. The marginal effect is 28 percentage points and statistically significant at the 1 percent level. The estimated effect is close to that obtained in the first column of Table 2 ( 25 percentage points).

In the second and third columns, we compare groups (a) and (b) to see how the negative first job effect (for those who did not find a job as a regular employee at graduation) on the employment status in the fourth year or later differs depending on whether an individual could find a job as a regular employee in the subsequent three year period after graduation. In the second column, in which we examine the first job effect for individuals in group (a), the marginal effect, at 46 percentage points, is positive and significant. On the other hand, as shown in the third column, the marginal effect for individuals in group (b), who were able to find a job as a regular employee in the three years after graduation, it is close to zero and insignificant. Therefore, while there appears to exist a first job effect for those who did not find a job as a regular employee at graduation, the effect disappears relatively quickly for those who were able to find a job as a regular employee at least once within three years after graduation.

The fourth and fifth columns compare groups (c) and (d) to see whether those successful in their job hunt at graduation enjoy an advantage irrespective of whether they retained their first job. The marginal effect reported in the fourth column is 24 percentage points, but statistically significant only at the 10 percent level, indicating that the probability of having a job as a regular employee in the fourth year or later may be only marginally higher for those successful in their job hunt at graduation if they lost or left their regular job to be a part-time worker or not in employment at least once within three years after getting a regular job at job market entry. However, in the case that an individual continues to work as a regular employee for three consecutive years after graduation, the probability of having a job as a regular employee 
in later years is a statistically significant 38 percentage points higher, as shown in the last column. Therefore, the results reported in the fourth and fifth columns indicate that the advantage of finding a job as a regular employee at graduation becomes much weaker for individuals who lose or leave the job they found at graduation.

To sum up, what really matters appears not to be finding a job as a regular employee at graduation but finding a job as a regular employee within a reasonable period of time from graduation. This finding suggests that the first job effect turns into a serious problem when a temporary business downturn becomes a protracted recession, as was the case during the so-called employment "ice age." In addition, the observed path dependency of the first job effect shown in this subsection indicates that the stigma (negative signaling) attached to the failure of finding a job during the initial job hunt at graduation (rather than the accumulation of human capital or skills through work experience) plays an important role in the first job effect. In Japan, where lifetime employment is considered to be the norm, the failure of finding a regular job at graduation, or leaving a regular job within a few years of graduation, is potentially regarded as a negative signal about the quality of such individuals.

\section{Conclusions}

Using annual career records of female workers constructed from micro-data of the Japanese Panel Survey of Consumers, this paper examined how finding a job as a regular employee at graduation matters for an individual's future job career. We confirm that an individual's job status at graduation matters significantly for the future job status (i.e., regular job or not) even for female workers in Japan. The effect gradually declines and effectively disappears within around ten years from graduation. Moreover, the observed first job effect depends on the post-graduation career path taken by the individual: the future job opportunities for individuals who were able to find a job as a regular employee within three years of graduation - even if they failed to find a job as a regular employee during their job hunt at graduation - were not significantly different from those for individuals who got a job as a regular employee at graduation.

These empirical findings provide some clues to help our understanding of the mechanisms 
underlying the negative cohort effect associated with entering the labor market during a recession and provide some indications for a policy response in prolonged recessions such as during the employment "ice age." As for the background mechanisms, it can be argued that the burden of the negative cohort effect from a recession falls disproportionately on individuals who were unsuccessful in their first job hunt (rather than falling evenly on all individuals in that cohort). Moreover, our finding that the first job effect becomes irrelevant once an individual is fortunate enough to find a job as a regular employee within a reasonable time period after graduation suggests that the first job effect results at least partially from the negative signal or stigma attached, in the context of the Japanese employment system, to having been unsuccessful in the first round of job hunting at graduation.

Our findings also highlight the need for policies to assist those who lose out in the "first" job hunt, especially when the economy is experiencing prolonged stagnation such as the during "lost decade" or the employment "ice-age." As it appears to be possible for individuals to make up for the negative effect caused by the bad luck of graduating when macroeconomic conditions are unfavorable if they can find a job as a regular employee within a reasonable time period, systematic policies to provide support for the employment of young workers who failed to find a (good) job in their first round of job hunting could provide substantial benefits. In this context, the recent proposal by the Japan Association of Corporate Executives (Keizai Doyukai) that recruiting firms should treat all workers that have graduated within less than three years as if they were new graduates is an encouraging step in the right direction. 


\section{References}

Bowlus, Audra J. (1995) "Matching Workers and Jobs: Cyclical Fluctuations in Match Quality," Journal of Labor Economics, Vol. 13, No. 2, pp. 335-350.

Brunner, Beatrice, and Andreas Kuhn (2009) "To Shape the Future: How Labor Market Entry Conditions Affect Individuals' Long-Run Wage Profiles," IZA Discussion Paper Series, No. 4601.

Genda, Yuji, Ayako Kondo and Souichi Ohta (2010) "Long-Term Effects of a Recession at Labor Market Entry in Japan and the United States,” Journal of Human Resources, Vol. 45, No. 1, pp. 157-196.

Genda, Yuji, and Masako Kurosawa (2001) "Transition from School to Work in Japan," Journal of the Japanese and International Economies, Vol. 15, No. 4, pp. 465-488.

Kahn, Lisa B. (2010) "The Long-Term Labor Market Consequences of Graduating from College in a Bad Economy," Labour Economics, Vol. 17, No. 2, pp. 303-316.

Kondo, Ayako (2007) "Does the First Job Really Matter? State Dependency in Employment Status in Japan," Journal of the Japanese and International Economies, Vol. 21, No. 3, pp. 379-402.

Kondo, Ayako (2008) "The Long-Term Effects of a Recession at Entry to the Labor Market: Comparison Between Japanese and American Women (Rodoshijo Sannyuji no Fukyo no Chokiteki Eikyo: Nichibei Josei no Hikaku Bunseki)," Kikan Kakei Keizai Kenkyu, Vol. 77, pp.73-80 (in Japanese).

Ohtake, Fumio, and Takenori Inoki. (1997) "Cohort Effects in the Labor Market (Rodoshijo ni okeru Sedai Kouka)," in Asako, Kazumi, Shinichi Fukuda and Naoyuki Yoshino, eds., Gendai Macro Keizai Bunseki, Univ. of Tokyo Press, Tokyo (in Japanese).

Oreopoulos, Phillip, Till von Wachter and Andrew Heisz (2006) "The Short- and Long-Term Career Effects of Graduating in a Recession: Hysteresis and Heterogeneity in the Market for College Graduates," NBER Working Paper, No. 12159.

Oyer, Paul (2006) "The Macro-Foundations of Microeconomics: Initial Labor Market Conditions and Long-Term Outcomes for Economists," NBER Working Paper, No. 12157.

The Japan Institute for Labour Policy and Training (2005), "Report on Recruiting 'Recent Graduates' (Dai-ni Shinsotsusha no Saiyo Jittai Chosa)," JILPT Research Reports, No. 3. 
Table 1. Basic statistics

Table 1. Basic Statistics

\begin{tabular}{|c|c|c|c|}
\hline & Whole sample & $\begin{array}{l}\text { High-school } \\
\text { graduates }\end{array}$ & $\begin{array}{c}\text { College graduates } \\
\text { or higher }\end{array}$ \\
\hline Total number of observations & $21,666 \quad(100.0)$ & $11,614 \quad(100.0)$ & $10,052(100.0)$ \\
\hline \multicolumn{4}{|l|}{ Current employment status } \\
\hline Regular & $10,387 \quad(47.9)$ & $5,142 \quad(44.3)$ & $5,245 \quad(52.2)$ \\
\hline Non-regular & $4,358 \quad(20.1)$ & $2,669 \quad(23.0)$ & $1,689 \quad(16.8)$ \\
\hline Not in employment & $6,921 \quad(31.9)$ & $3,803 \quad(32.7)$ & $3,118 \quad(31.0)$ \\
\hline \multicolumn{4}{|l|}{ Employment status at graduation } \\
\hline Regular & $17,226 \quad(79.5)$ & $8,990 \quad(77.4)$ & $8,236 \quad(81.9)$ \\
\hline Non-regular & $3,134 \quad(14.5)$ & $1,957 \quad(16.9)$ & $1,177 \quad(11.7)$ \\
\hline Not in employment & $1,306 \quad(6.0)$ & $667 \quad(5.7)$ & $639 \quad(6.4)$ \\
\hline Married & $11,718 \quad(54.1)$ & $6,515 \quad(56.1)$ & $5,203 \quad(51.8)$ \\
\hline With children & $9,144 \quad(42.2)$ & $5,317 \quad(45.8)$ & $3,827 \quad(38.1)$ \\
\hline Number of children (average) & 1.8 & 1.8 & 1.7 \\
\hline With children aged 6 and below & $7,104 \quad(32.8)$ & $4,135 \quad(35.6)$ & $2,969 \quad(29.5)$ \\
\hline Number of children aged 6 and below (average) & 1.4 & 1.5 & 1.4 \\
\hline With children aged 7 to 18 & $3,706 \quad(17.1)$ & $2,246 \quad(19.3)$ & $1,460 \quad(14.5)$ \\
\hline Number of children aged 7 to 18 (average) & 1.4 & 1.6 & 1.6 \\
\hline Years since graduation (average) & 8.5 & 9.0 & 8.0 \\
\hline Age (average) & 28.3 & 27.4 & 29.4 \\
\hline
\end{tabular}


Table 2. Effect of obtaining a regular job at graduation on likelihood of regular employment at present

\begin{tabular}{|c|c|c|c|}
\hline \multirow[t]{3}{*}{ Dependent variable } & \multicolumn{3}{|c|}{ Current employment status (regular: $y_{i t}=1$; otherwise: $y_{i t}=0$ ) } \\
\hline & (1) & (2) & (3) \\
\hline & Whole sample & $\begin{array}{l}\text { High-school } \\
\text { graduates }\end{array}$ & $\begin{array}{c}\text { College graduates } \\
\text { or higher }\end{array}$ \\
\hline Marginal effect of first job & $\begin{array}{l}0.252^{* * *} \\
(0.040)\end{array}$ & $\begin{array}{l}0.224^{* * *} \\
(0.048)\end{array}$ & $\begin{array}{c}0.336^{* * *} \\
(0.069)\end{array}$ \\
\hline \multicolumn{4}{|l|}{ Coefficients (second stage equation) } \\
\hline Employment status at graduation $\left(x_{i}\right)$ & $\begin{array}{l}0.665^{* * *} \\
(0.116)\end{array}$ & $\begin{array}{l}0.606^{* * *} \\
(0.143)\end{array}$ & $\begin{array}{l}0.889^{* * *} \\
(0.208)\end{array}$ \\
\hline Married & $\begin{array}{l}-1.021^{* * *} \\
(0.054)\end{array}$ & $\begin{array}{l}-0.926^{* * *} \\
(0.073)\end{array}$ & $\begin{array}{l}-1.119^{* * *} \\
(0.081)^{*}\end{array}$ \\
\hline With children aged 6 and below & $\begin{array}{l}-0.500 * * * \\
(0.090)\end{array}$ & $\begin{array}{l}-0.489^{* * *} \\
(0.126)\end{array}$ & $\begin{array}{l}-0.509^{* * *} \\
(0.128)^{2}\end{array}$ \\
\hline Number of children aged 6 and below (average) & $\begin{array}{l}-0.165^{* * *} \\
(0.058)\end{array}$ & $\begin{array}{l}-0.216^{* * *} \\
(0.082)\end{array}$ & $\begin{array}{r}-0.117 \\
(0.081)\end{array}$ \\
\hline With children aged 7 to 18 & $\begin{array}{l}-0.031 \\
(0.115)\end{array}$ & $\begin{array}{l}-0.025 \\
(0.158)\end{array}$ & $\begin{array}{r}-0.042 \\
(0.161)\end{array}$ \\
\hline Number of children aged 7 to 18 (average) & $\begin{array}{r}-0.095 \\
(0.072)\end{array}$ & $\begin{array}{r}-0.037 \\
(0.095)\end{array}$ & $\begin{array}{l}-0.178 * \\
(0.107)\end{array}$ \\
\hline Years since graduation & $\begin{array}{l}-0.069 * * * \\
(0.025)\end{array}$ & $\begin{array}{r}0.004 \\
(0.041)\end{array}$ & $\begin{array}{l}-0.089^{* * *} \\
(0.033)^{2}\end{array}$ \\
\hline College graduate or higher & $\begin{array}{l}-0.000 \\
(0.088)\end{array}$ & - & - \\
\hline Regional unemployment rate & $\begin{array}{l}-0.168^{* * *} \\
(0.035)\end{array}$ & $\begin{array}{l}-0.229^{* * *} \\
(0.047)\end{array}$ & $\begin{array}{l}-0.100 * \\
(0.053)\end{array}$ \\
\hline First stage equation & & & \\
\hline Regional unemployment rate at graduation $\left(v_{\mathrm{i}}\right)$ & $\begin{array}{l}-0.132^{* * *} \\
(0.042) \\
\end{array}$ & $\begin{array}{l}-0.132 * \\
(0.068) \\
\end{array}$ & $\begin{array}{l}-0.134^{* *} \\
(0.054) \\
\end{array}$ \\
\hline$\rho$ & $\begin{array}{r}-0.071 \\
(0.049) \\
\end{array}$ & $\begin{array}{r}-0.085 \\
(0.056) \\
\end{array}$ & $\begin{array}{r}-0.146 \\
(0.102) \\
\end{array}$ \\
\hline Wald $\chi^{2}$ & $1540.2^{* * *}$ & $934.5^{* * *}$ & $689.7^{* * *}$ \\
\hline Number of observations & 21,666 & 11,614 & 10,052 \\
\hline Number of hous eholds & 1,830 & 869 & 961 \\
\hline
\end{tabular}

Notes:

1. The marginal effects are calculated as $\operatorname{Pr}(y=1 \mid x=1)-\operatorname{Pr}(y=1 \mid x=0)$ evaluated at the mean of other covariates. 2. Standard errors of coefficients clustered by individual are shown in parentheses. ***,**, and * denote significance at the 1, 5, and 10 percent level, respectively. Year dummies, age, and age squared are included in the second stage equation. The first column includes a dummy for higher education (college or higher) in the first stage equation. 
Table 3. Path dependence of first job effects

\begin{tabular}{|c|c|c|c|c|c|}
\hline & (1) & (2) & (3) & (4) & (5) \\
\hline & \multirow{2}{*}{$\begin{array}{l}\text { Results of Table } 2(1) \\
\text { using observations } \\
\text { more than } 3 \text { years } \\
\text { since graduation }\end{array}$} & \multicolumn{2}{|c|}{$\begin{array}{l}\text { Comparison between those who were not } \\
\text { a regular employee at entry }\end{array}$} & \multicolumn{2}{|c|}{$\begin{array}{l}\text { Comparison between those who were a } \\
\text { regular employee at entry }\end{array}$} \\
\hline & & $\begin{array}{l}\text { Not regular during } \\
\text { the first } 3 \text { years after } \\
\text { graduation }\end{array}$ & $\begin{array}{l}\text { Were regular at least } \\
\text { once during the first } \\
3 \text { years after } \\
\text { graduation }\end{array}$ & $\begin{array}{l}\text { Left regular } \\
\text { employment at least } \\
\text { once during the first } \\
3 \text { years after }\end{array}$ & $\begin{array}{l}\text { Were regular during } \\
\text { the first } 3 \text { years after } \\
\text { graduation }\end{array}$ \\
\hline \multicolumn{6}{|l|}{ Estimated groups } \\
\hline for groups $x_{i}=0$ & $\mathrm{a} \& \mathrm{~b}$ & $\mathrm{a}$ & $\mathrm{b}$ & $\mathrm{a} \& \mathrm{~b}$ & $a \& b$ \\
\hline for groups $x_{i}=1$ & $\mathrm{c} \& \mathrm{~d}$ & $\mathrm{c} \& \mathrm{~d}$ & $\mathrm{c} \& \mathrm{~d}$ & $\mathrm{c}$ & $\mathrm{d}$ \\
\hline$\overline{\text { Marginal effect of first job }}$ & $\begin{array}{l}0.277 * * * \\
(0.081)\end{array}$ & $\begin{array}{c}0.464 * * * \\
(0.032)\end{array}$ & $\begin{array}{c}0.002 \\
(0.178)\end{array}$ & $\begin{array}{l}0.235^{*} \\
(0.139)\end{array}$ & $\begin{array}{c}0.378 * * * \\
(0.085)\end{array}$ \\
\hline$\rho$ & $\begin{array}{l}-0.175 \\
(0.128) \\
\end{array}$ & $\begin{array}{l}-0.127 \\
(0.119) \\
\end{array}$ & $\begin{array}{l}-0.107 \\
(0.208)\end{array}$ & $\begin{array}{l}-0.788^{*} \\
(0.405)\end{array}$ & $\begin{array}{l}-0.195 \\
(0.139)\end{array}$ \\
\hline Wald $\chi^{2}$ & $754.2 * * *$ & $708.5^{* * *}$ & $728.8 * * *$ & $239.6 * * *$ & $703.7^{* * *}$ \\
\hline Number of observations & 6,384 & 5,810 & 5,859 & 2,254 & 5,229 \\
\hline Number of individuals & 912 & 830 & 837 & 322 & 747 \\
\hline
\end{tabular}

Note: See notes in Table 2. Groups (a) to (d) follow the definitions listed below. Observations include a fixed set of individuals up to ten years after graduation.

\begin{tabular}{|c|c|c|c|c|}
\hline Group & Employment status at graduation & $\begin{array}{c}\text { Path dependency for } 3 \text { years after } \\
\text { graduation }\end{array}$ & $\begin{array}{c}\text { Number of } \\
\text { observations }\end{array}$ & $\begin{array}{l}\text { Number of } \\
\text { individuals }\end{array}$ \\
\hline $\mathrm{a}$ & \multirow{2}{*}{$\begin{array}{l}\text { Not regular or without occupation } \\
\qquad\left(x_{i}=0\right)\end{array}$} & Never regular & 525 & 75 \\
\hline $\mathrm{b}$ & & Were regular at least once & 574 & 82 \\
\hline $\mathrm{c}$ & \multirow{2}{*}{$\operatorname{Regular}\left(x_{i}=1\right)$} & Left regular at least once & 1,155 & 165 \\
\hline $\mathrm{d}$ & & Continued to be regular & 4,130 & 590 \\
\hline
\end{tabular}

Figure 1. Marginal effect of the first job on current employment status

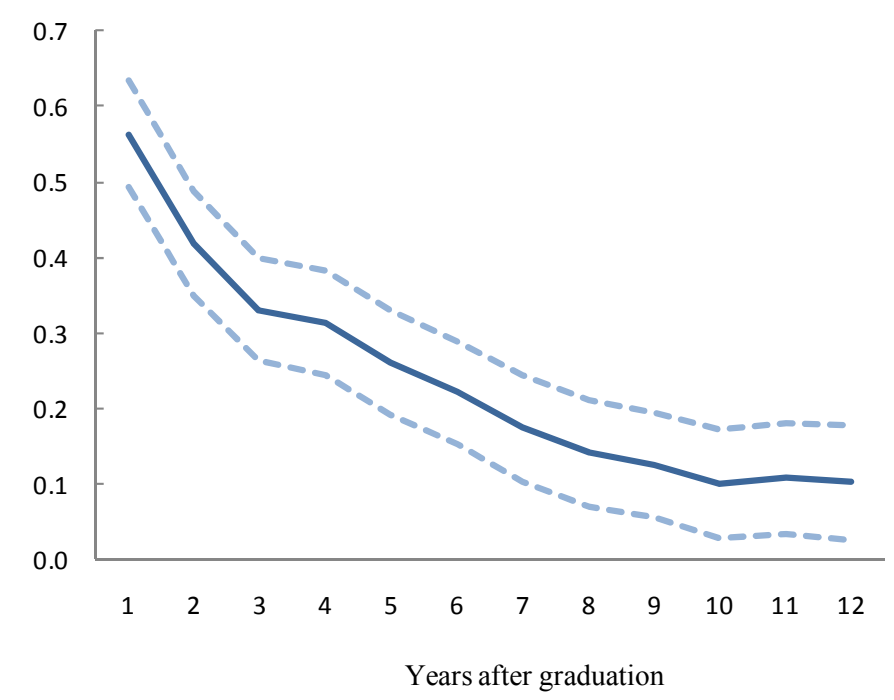

Note: See Table A.2 for detailed results. 


\section{Appendix 1. Construction of the dataset using information on job histories}

Although this paper aims to examine the persistence and path dependency of the first job effect, the number of observations on individuals a few years after their graduation is substantially limited in the JPSC because it only covers females aged 24 and over. To fill this gap, we expand our database by using past information on individuals available from the survey.

With regards to the current employment status, the JPSC asks each respondent whether she is (a) employed; (b) self-employed, working for a family business, or as an independent professional; (c) a homeworker; (d) a student; or (e) not in employment. And for those who select the first choice, there is a further question asking whether they are (a) a regular employee; (b) a part-time worker; or (c) a temporary worker. Thus, we can define regular employees as those who select the first choice in the second question. The remaining observations in our database consist of respondents who replied they were a part-time or a temporary worker in the second question and those who replied they were "not in employment" in the first question.

In addition, the JPSC in the first or second panel for each respondent asks questions on their past employment status since graduation, which we use in order to expand our database back to respondents' year of graduation. The JPSC also asks respondents, when they join the panel, about the number and age of their children (for up to five children) as well as the year of their marriage (if they are married). Thus, we regard respondents as single up to the year they got married and as married thereafter. In order to obtain the number and ages of children before respondents joined the panel, we calculate backward the age of each child for each year by subtracting one for each year from the age of a child (available in the first panel) until age zero, i.e., when the child was born.

Figure A.1 shows the number of observations in the dataset before and after these procedures. The number of observations considerably increases, especially for years immediately after graduation. Table A.1 presents basic statistics of the JPSC data before the expansion. Among other differences, respondents in the JPSC data are older by three to four years than in the expanded dataset underlying Table 
1 due to the lack of observations for younger individuals immediately after their graduation.

Figure A.1 Number of observations in the dataset before and after using respondents' job history record

High-school graduates

College graduates or higher
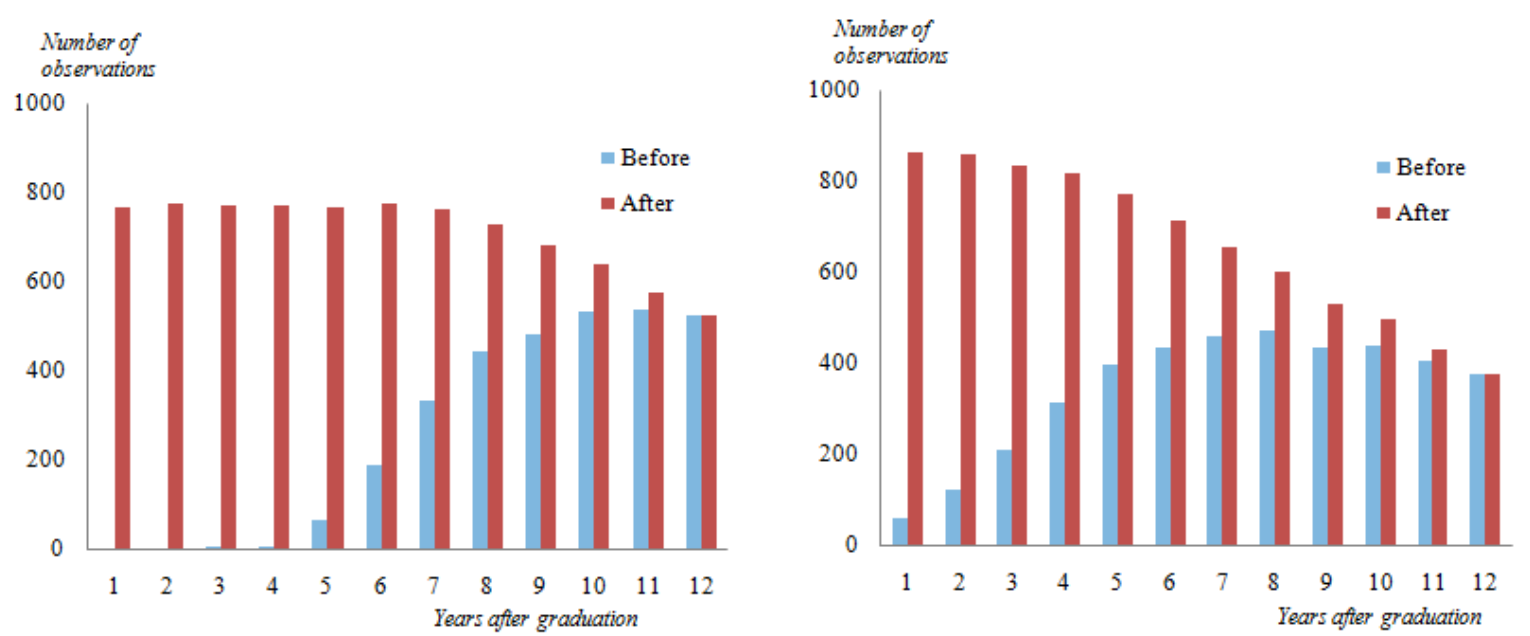

Table A.1 Basic statistics (Before using respondents' job history record)

Table A.1 Basic statistics (Before using respondents' job history record)

\begin{tabular}{|c|c|c|c|c|c|c|}
\hline \multirow[b]{2}{*}{ Total number of observations } & \multicolumn{2}{|c|}{ Whole sample } & \multicolumn{2}{|c|}{$\begin{array}{l}\text { High-school } \\
\text { graduates }\end{array}$} & \multicolumn{2}{|c|}{$\begin{array}{c}\text { College graduates } \\
\text { or higher }\end{array}$} \\
\hline & 12,420 & $(100.0)$ & 6,194 & $(100.0)$ & 6,226 & $(100.0)$ \\
\hline \multicolumn{7}{|l|}{ Current employment status } \\
\hline Regular & 4,520 & $(36.4)$ & 1,780 & $(28.7)$ & 2,740 & $(44.0)$ \\
\hline Non-regular & 2,792 & $(22.5)$ & 1,716 & $(27.7)$ & 1,076 & $(17.3)$ \\
\hline Not in employment & 5,108 & $(41.1)$ & 2,698 & $(43.6)$ & 2,410 & $(38.7)$ \\
\hline \multicolumn{7}{|l|}{ Employment status at graduation } \\
\hline Regular & 9,994 & $(80.5)$ & 4,878 & $(78.8)$ & 5,116 & $(82.2)$ \\
\hline Non-regular & 1,662 & $(13.4)$ & 977 & $(15.8)$ & 685 & $(11.0)$ \\
\hline Not in employment & 764 & $(6.2)$ & 339 & $(5.5)$ & 425 & $(6.8)$ \\
\hline Married & 8,585 & $(69.1)$ & 4,688 & $(75.7)$ & 3,897 & $(62.6)$ \\
\hline With children & 7,259 & $(58.4)$ & 4,118 & $(66.5)$ & 3,141 & $(50.4)$ \\
\hline Number of children (average) & \multicolumn{2}{|c|}{1.9} & \multicolumn{2}{|l|}{1.9} & \multicolumn{2}{|c|}{1.8} \\
\hline With children aged 6 and below & 5,232 & $(42.1)$ & 2,948 & $(47.6)$ & 2,284 & $(36.7)$ \\
\hline Number of children aged 6 and below (average) & \multicolumn{2}{|c|}{1.5} & \multicolumn{2}{|c|}{1.5} & \multicolumn{2}{|c|}{1.4} \\
\hline With children aged 7 to 18 & 3,644 & $(29.3)$ & 2,202 & $(35.6)$ & 1,442 & $(23.2)$ \\
\hline Number of children aged 7 to 18 & \multicolumn{2}{|c|}{1.6} & \multicolumn{2}{|c|}{1.6} & \multicolumn{2}{|c|}{1.6} \\
\hline Years since graduation (average) & 11.9 & & 13.1 & & 10.7 & \\
\hline Age (average) & 31.9 & & 31.6 & & 32.2 & \\
\hline
\end{tabular}




\section{Appendix 2. Background estimation results of Figure 1}

Table A.2 Effect of obtaining a regular job at graduation on likelihood of regular employment at present

\begin{tabular}{|c|c|}
\hline \multicolumn{2}{|l|}{ Dependent variable } \\
\hline Marginal effect of first job & \\
\hline 1st year since graduation & $0.563(0.071) * * *$ \\
\hline 2nd year since graduation & $0.419(0.070)^{* * *}$ \\
\hline $3 r d$ year since graduation & $0.331(0.069)^{* * *}$ \\
\hline 4th year since graduation & $0.314(0.069)^{* * *}$ \\
\hline 5th year since graduation & $0.261(0.069)^{* * *}$ \\
\hline 6th year since graduation & $0.221(0.067)^{* * *}$ \\
\hline 7th year since graduation & $0.174(0.069)^{* *}$ \\
\hline 8th year since graduation & $0.141(0.070)^{* *}$ \\
\hline 9th year since graduation & $0.124(0.069) *$ \\
\hline 10th year since graduation & $0.100 \quad(0.072)$ \\
\hline 11th year since graduation & $0.108 \quad(0.072)$ \\
\hline 12th year since graduation & $0.102 \quad(0.075)$ \\
\hline \multicolumn{2}{|l|}{ Coefficients (second stage equation) } \\
\hline \multicolumn{2}{|l|}{ Employment status at graduation $\left(x_{i}\right)$} \\
\hline *Ist year since graduation (dummy variable) & $1.790(0.210)^{* * *}$ \\
\hline *2nd year since graduation (dummy variable) & $1.330(0.210)^{* * *}$ \\
\hline *3rd year since graduation (dummy variable) & $1.052(0.209)^{* * *}$ \\
\hline *4th year since graduation (dummy variable) & $0.997(0.210)^{* * *}$ \\
\hline *5th year since graduation (dummy variable) & $0.828(0.214)^{* * *}$ \\
\hline *6th year since graduation (dummy variable) & $0.703(0.209)^{* * *}$ \\
\hline *7th year since graduation (dummy variable) & $0.552(0.216) * *$ \\
\hline *8th year since graduation (dummy variable) & $0.447(0.220) * *$ \\
\hline *9th year since graduation (dummy variable) & $0.395(0.217) *$ \\
\hline *10th year since graduation (dummy variable) & $0.316(0.225)$ \\
\hline *11th year since graduation (dummy variable) & $0.342(0.227)$ \\
\hline *12th year since graduation (dummy variable) & $0.322(0.236)$ \\
\hline Married & $-0.895(0.053)^{* * *}$ \\
\hline With children aged 6 and below & $-0.758(0.101)^{* * *}$ \\
\hline Number of children aged 6 and below (average) & $-0.137(0.064)^{* *}$ \\
\hline With children aged 7 to 18 & $-0.049(0.288)$ \\
\hline Number of children aged 7 to 18 (average) & $-0.072(0.236)$ \\
\hline College graduates or higher & $0.027(0.088)$ \\
\hline Regional umemployment rate & $-0.177(0.036)^{* * *}$ \\
\hline \multicolumn{2}{|l|}{ First stage equation } \\
\hline Regional unemployment rate at graduation $\left(v_{i 1}\right)$ & $-0.181(0.039)^{* * *}$ \\
\hline$\underline{\rho}$ & $-0.079(0.113)$ \\
\hline Wald $\chi^{2}$ & $1705.7 * * *$ \\
\hline Number of observations & 16,473 \\
\hline Number of individuals & 1,829 \\
\hline
\end{tabular}

Notes:

1. The marginal effects are calculated as $\operatorname{Pr}(y=1 \mid x=1)-\operatorname{Pr}(y=1 \mid x=0)$ evaluated at the mean of other covariates.

2. The standard errors of coefficients clustered by each individual are shown in parentheses. $* * *, * *$, and $*$ denote significance at the 1,5 , and 10 percent level respectively. Year dummies, age and age squared are included in the second stage equation. 